WORKING PAPERS OF THE

CENTER FOR RESEARCH. ON SOCIAL. ORGANIZATION

DEPARTMENT OF SOCIOLOGY.

UNIVERSITY OF MICHIGAN

Paper \#18

September, 1966 
THE STUDY OF DEVIANT BEHAVIOR: WHERE THE ACTION IS

\author{
Presidential Address, Twenty-Eight Annual \\ Meeting of The Ohio Valley Sociological \\ Society, Dayton, Ohio, April 29, 1966 \\ Forthcoming, The Ohio Valley Sociologist
}

Dr.'Albert J.'Reiss, Jr. 


\section{The Study of Deviant Behavior: Where the Action Is*}

The early American sociologists wrote unabashedly about social pathology and the action lay in social reform. Indeed it was not uncommon for sociologists at the turn of the century to be actively engaged in reform movements, often with only a second hand acquaintance with ideas concerning that which they would reform. Some were among the severest critics of the established order and a few lost their jobs to their principles.

But the scene changed and with it the action: Sociologists studied social problems and the more sophisticated wrote more or less dispassionately of social movements and of personal and social disorganization. Particularly within the Chicago school the action shifted to "making the scene". Sociologists made their naturalistic observations without quite going native. Though not without involvement in changing the established order, their analyses were cloaked within the terminology of personal and social reorganization and the stages of social movements. They were more likely than not to renounce reform.

Beginning in the mid-thirties the stage, the scene, and even to a degree the actors shifted. Interest in the study of social movements declined; almost disappeared. The action began to lie in a "...systematic approach to the analysis of social and cultural sources of deviant behavior."l Writing in 1938 Merton signaled the shift in action, stating:

"Our: primary aim is to discover how some social structures exert a definite pressure upon certain persons in the society to engage in nonconformist rather than conformist conduct. $! 2$ 
He argued that our sociological task was to explain variation in rates of deviant behavior, not its incidence, and he introduced functional theory by way of explanation.

While the action lay in investigating cultural and social structure, there is no mistaking the fact that deviance was defined as the behavior or conduct of people, their modes of adaptation to cultural goals and institutịonalized means. Later developments of the theory while elaborating the theory of social structure emphasizing differential opportunities, -and while elaborating the theory of cultural structure to emphasize subcultures have left the definition of deviance as behavior or conduct of people unchanged.

Beginning, with the 60's there have been growing signs. of." dissatisfaction with both the definition of deviance and the explanatory variables: The main thrust of this criticism whether by Albert Cohen, Erving Goffman, or Howard Becker ${ }^{3}$ has been the failure of the theory to regard deviance as a process or persons becoming labeled as deviant and a concern with organizational responses or adaptation to deviance, an idea that earlier was central to the writings of Clifford Shaw.

Becker's and Goffman's approaches to the study of deviance perhaps are the most serious attempt to redefine the action, both in their reformulation of the problem and in their call for sociologists who study deviance to once again "make the scene" in their investigations. Becker's definition of deviance is cited to. illustrate the shift in action: 
"...social groups create deviance by making the rules whose infractions constitute deviance, and by applying those rules to particular people and labeling them as outsiders. From this point of view, deviance is not a quality of the act the person commits, but rather a consequence of the application by others of rules and sanctions to an "effender". 4

The action for Becker and others has..shifted somewhat from the investigation of cultural and social structure per se to investigation of "...the process of interaction between people, some of whom in the service of their interests make and enforce rules which catch others who, in the service of their own interests, have committed acts which are labeled as deviant." 5 Added to the emphasis on interaction is one on enterprise in an organizational sense. As Becker states:

"... whenever rules are created and applied, we expect that the process of enforcement will be shaped by the complexity of the organization, resting on a basis of shared understandings in simpler groups and resulting from political maneuvering and bargaining in complex structures."

I would call your attention here to the development of the idea that organization is a crucial element both in the moral crusade, and in shaping the process of rule enforcement. While the action then appears to have shifted to the investigation of interaction in an organizational context, there still is no mistaking the fact that deviance is defined in terms of the application of rules to particular people and a labeling of them as outsiders.

By now it should be apparent that although I have highlighted the shifts in where the action is in theory and research on deviance, I also have emphasized that the definition of 
deviance has focused on the behavior of persons who are defined or labeled as deviant. My purpose in doing so is to call attention to the fact that more is involved in the study of deviance than the explanation of variation in the rates of deviant behavior of persons or of the moral enterprise involved in the creation and enforcement of rules related, to the behavior of persons. More. is involved because deviance characterizes the actions of aggregates and organized groups and what we have come to call formal organizations quite apart from the defined deviance of individuals who comprise their membership or hold an official position in them. Though I dislike the term, I am referring to what sometimes is called the "behavior of organizations." activity that is evaluated by moral enterprise and labeled as deviant. It is to this matter that I now turn; suggesting that a more general theory will concern itself not only with the behavior of persons but of organizations.

What I shall say about organizational deviance first must be understood by discussing several forms of deviance that. apparently are similar to, or an aspect of, organizational deviance. One of these is referred to as "institutionalized" or "patterned evasion".

Institutionalized or patterned evasion is said to occur in those cases."... where a publicly accepted norm is covertly violated on a large scale, with the tacit acceptance or, even. approval of the same society.or group, at least so long as the violation is concealed." 7 Examples commonly referred to as patterned evasion are income tax evasion, sharp business 
practices, drinking wet and voting dry, and some of the patterns of sex behavior reported in the Kinsey studies. Common to all patterned evasion is the element of individual behavior deviating from norms and institutional support for the deviation so long as it is not processed before an open public.

Though this is not the place to develop the matter; I want to suggest that there are at least two major and different forms of patterned evasion. In the first type the patterning arises largely from an aggregative effect of individuals deviating from norms, their evasion carries relatively low risk of detection, and at: least moderate cultural support if not publically processed. There is relatively little by way of organized relations among the individuals who deviate, however, and even relatively little formal organizational implementation of the deviant action itself. This is true, for example, of much institutionalized income tax evasion, sharp business practices, cheating in the classroom, and some forms of sex deviation. Premarital sex relations, for example, are all right so long as you don't get pregnant or have a child out of wedlock.

The second type involves a more elaborate and complex organizational system that makes mass evasion possible. The organization itself may be more liable to negative sanctioning than the individuals who evade. Furthermore, individuals or organizations who cater to the interest of the mass who evade may need considerable organizational support in the form of bribes, fixes, and protection if they are to operate. This is true for much of the kind of deviance we call vice that is catered to be what is 
loosely referred to as organized crime. Much organized crime thrives on institutionalized evasion--buying liquor in a dry area or illegal betting for example. Indeed any form of mass evasion will necessarily be quite different if there is no organized vehicle for its practice.

Though the litterature tends to confuse the matter, it is important in these cases to distinguish the deviance of the organization from the patterned deviance of the clients. They pose quite different problems for rule makers and enforcers in the system since the client system generally is only loosely integrated with the organized service system. Police action, for example, more generally is directed against the operators and their business rather than against the clients in most vice activity.

A word needs to be said, too, about what Edwin Sutherland defịned as white-collar crime. Sutherland was acutely aware of the fact that what he termed white-collar crime involved organizations as well as individuals. His paper."Is "White-Collar Crime" Crime?" published in 1945 analyzes the decisions by courts and commissions against the 70 largest industrial and mercantile corporations in the United States for four types of laws. 8 Despite this organizational starting point, his primary concern in the paper is with. white-collar criminals, particularly businessmen and he discusses such matters as the differential status of the businessmen and the stigma of the crime attached to the offenders. Not unaware of organizational factors in white-collar crime, it appears that analysis of the crime of the organization, per se, was somewhat alien to his approach. 
I have said that my main purpose is to argue for the use of a more general theory that encompasses the deviant behavior of organizations as well as of persons. The remarks that. follow are directed toward exploring the more general relations of social organization to devịant behavior leading up to a consideration of the deviant organization.

The social-psychological approach to deviance has generally considered any person as deviant whose behavior departs from normative expectations. This concern with deviance as behavior departing from normative expectations had led social-psychologists into a concern for the comparison of deviants with conformers. Their bete noire has been the fact that societal organization has not produced for them the necessary data on all deviants of a given kind, e.g., all criminals, or even all homicides. This hás led them into the pursuit of the "hidden" deviant--the hidden delinquent, the "white-collar" criminal; the closet sexual offendert. Interestingly enough generally this search has been carried out only where social organization makes it fairly easy to detect the "hidden" deviants. "There has been little searching for types of deviants that the social organization coerces almost entirely into a hidden or secret position--the subversives, the "closet fags," the members of an "underground," or spys to give a few illustrations.:

This search for the "hidden" deviant as well as those who are processed withị-some organizational context and therefore accessible to investigation has occurred primarily because of an interest in the deviant person; or at mọt an interest in 
explaining why deviant persons occur where they do within a: structural system. Parenthetically: I might say that students of cultural and social structure might find it far more worthwhile to explain differences between "hidden!". and "known" delinquents in terms of the organizational system that produces these very differences rather than to try to aggregate all of the delinquents and explain variation in their occurrence in structural locations. But the point I wish to make here is. that like Becker and others. I find this approach severely limited from a sociological point of view precisely because deviance is defined in purely cultural and behavioral terms-that is, it is defined quite apart from social organization. When it is defined in organizational terms; the investigator is almost apologetic--these are only the "official" delinquents, or the. "offenders" who were incarcerated. He apologizes because he thinks he "knows" something is missing. But what is missing? For these theorists a norm and behavior is all that is essential. to the definition of deviance; there is no social organization related to the definition of deviance in this approach. Social organization, when it is introduced, is introduced as an explanation for the behavior.

Time does not permit me to pursue this point further, but. I simply want to suggest that from an organizational point of view, there is no deviant in a purely normative-behavioral sense. This is so for a number of reasons that I shall state briefly before moving on.

First, it is so because the social control systems in societies are differentially-organized in relation to deviance. 
It perhaps is mistaken to posit, as does Parson, that: "The theory of social control is the: obverse of the theory of the genesis of deviant behavior tendencies." 9 social control-sanctioning systems--are part and parcel. of the definition and genesis of deviant behavior.

Second, the definition of deviance, as well noted by Lemert;. Kitsuse, Becker and others, is a matter of societal reaction to deviance; it is a matter of organized processing of deviants, but also as I shall note below, of organizations. A central problem is to explain differences in who is processed as deviant and what difference this makes.

Third, deviant behavior itself bears a complex relationship to organizations. Yet in.simple terms, societal processing of deviants is partly a matter of the consequences of deviance for organization and organizations. Some forms of deviance are more clearly related to specific organizational contexts than others and the definition and processing of deviants arises precisely because of their relationship to organizations. To illustrate, check forgery and embezzlement are crimes against businesses. Malicious destruction of property is more often against an organization than an individual property owner so far as the definition and processing of deviants is concerned. Crimes against persons involve a victim and an offender; yet it is the criminal. who is most often studied rather than the relational system of victim and offender. A striking sociological fact for example is that a majority of reported rapes are for instances where there was a prior relationship between the victim and the offender. Rape of the person. where there is no prior relationship is relatively uncommon. 
I might say in thịs connection that from my point of view the investigation of the organizational relationship of deviants. should have a high priority in the study of deviance.' This ' would involve investigations of the relational properties of victims and offenders where victims are broadly defined to include formal organizations as well as persons. It is clear on the one hand that individual deviance may destroy organizations; it is equally clear that societal organization "protects" the victim from the deviant. It is within this context for example, that the institution and organization of insurance in modern societies assumes dominant proportions.

My first point then is that from the point of view of social organization (if not altogether by definition of what comprises a social system) while an individual may deviate from norms without any organization being deviant, there is no individual deviance that does not involve social interaction and organization. Perhaps this may appear to be saying no more than deviance in the Durkheim sense is a social fact. I am pressing however for the consideration of how organization enters into individual deviance as the primary. goal of the sociological study of deviance:

My second point is that much individual deviance is intricately linked to organized systems and organizations that also are defined as deviant. The illegal acts of persons are facịlitated if not altogether engendered by deviant organizational systems. 
What I am referring to in this second instance are those cases where persons engage in deviant acts, for example in gambling, in a client system that is defined as deviant--in this example a policy operation. Both the organization--here the policy operation and the client--here someone who buys. a number--then are deviant. To distinguish this from the third type, I shall shortly discuss, I want to emphasize that the behavior defined as deviant--in this example gambling--can occur under other organizational circumstances as well--for example, at a licensed track--that is, it can occur apart from a deviant service system.

Quite clearly then what is defined as vice serviced by a criminal organization falls within this category. Though time does not permit me to develop the point, from the standpoint of social control more effort is directed toward control of the organization--for example, policy--than to control the deviance of individuals who are clients; the persons who buy the numbers. This is especially true for forms of vice such as gambling where.the deviance of the dlients is generally disregarded, or for the illegal sale rather than the consumption of alcohol illegally manufactured; even of the use as against the manufacture or sale of narcotics. Indeed the sanctions at law against the client are considerabiy less punitive than those against members of the organizatión, or the organization itself. The bootlegger can looșe his entire investment and be individually sanctioned; the purchaser will generally go free.

The third way that organization and persons are related in. deviance occurs when the organization is defined as deviant in 
such a way as to classify all members or participants in it as deviant. A most important example of this type of deviance is what Smelser defines as the value-oriented social movement. 10 The value-oriented movement arises under conditions where the means for reconstituting the social order are closed off to persons, thereby turning their attention to a reconstitution of the value-organization of the system. Smelser includes in this class nativistic, messianic, millenerian, sectarian, utopian, and nationalistic movements as well as among others, political revolutions.: Though Smelser does not make the point, there is not only an implicit or explicit attack on the value system inherent in these movements but also an attack on the constitutive order that results in their being labeled as deviant and members by inclusion in them are labeled as deviant.

There; of course, is considerable variability in the degree to which a society may formally or legally define such movements and theị organizations as deviant. The "subversive" organization is a clear example of such a value-oriented movement and in our. own recent past the U. S. Attorney General's list of Subversive Organizations is a case in point. The Wobblies of the early 1900 's, The Bolshevik movement of the 20 's and the nativist movements of the 30's and $40^{\prime}$ 's are other examples of national concern with political subversion. American history provides ample illustration of national prẹccupation with organized subversion of its values, religious; political, and economic, not. to extend the list of examples.

Perhaps the best example of a study of this type of organizational deviance is Selznick's study, The Organizational 
Weapon, a study based on a more general theory of organizations. Selznick writes:

"It is a primary function of the constitutional order-whether of a particular organization or of the political community itself--to make power responsible by limiting the uses to which it may be put and specifying how it may be won. ...We shall speak of organizations and organizational practices as weapons when they are used by a power seeking elite. in a manner unrestrained by the constitutional order of the arena in. which the contest takes place." In this usage, "weapon" is not meant to denote any political tool, but one torn from its normal context and unacfeptable to the community as a legitimate mode of action."I That is as much a language for the study of deviant organizations perhaps as we have in the literature and it serves as a basis for the study of Bolshevik strategy and tactics--an organizational problem.

The fourth way that persons and organizations are linked in deviance occurs when the organization is defined as deviant but only those members who can be specifically charged with behavioral participation are defined as deviant. International. law provides some interesting cases in points. Certain of the trials at Neurenberg are of this order and even the Eichmann trail fits in some respects. From a sociological point of view, one should not be misled by the fact that in the specific drama where the individual is tried as deviant, he in all likelihood is accused of specific crimes as well. For the drama begins with an indictment of the organizational system as deviant and some are held more responsible than others.

The fifth way that persons and organizations are linked in deviance occurs when the organization is defined as deviant as a consequence of the behavior of some of its members. I suppose we all immediately think in this context of the classic cases of corrupt government or organizations--the scandal in a formal 
organization. Thus the traffic bureau or the police department is defined as corrupt. The organization undergoes some organizational transformation as a consequence and some of its members are removed from their office or position, even indicted and perhaps sentenced. There are other examples that readily come to. mind. One of the more recent to come to public attention involved price-fixing among the electrical companies. The major electrical companies were fined and in other ways sanctioned for the behavior of officials; a few officials were indicted, tried and sentenced.

The final way that individuals and organizations are linked in deviance occurs when the organization is defined and sanctioned as deviant, but the individual participants are not so regarded. While from a sociological point of view there can be no organization without behavior of individuals, the point here is that none of the individuals in the organization are defined as deviant for the behavior they engaged in, behavior that is related to the organization being defined as deviant. Let me illustrate with several examples from our recent past.

The current civil rights movement provides several cases in point. State commissions against discrimination in employment, housing, and civil rights generally spend the bulk of their time in defining and sanctioning organizations as deviant. An. employing establishment will be defined as discriminating against minorities and sanctioned for it. Yet the personnel officer who does the hiring, the officials who set the policy, or the workers who engage in discriminatory practice are under these conditions not defined as deviants and sacntioned for their behavior. 
Segregation of public facilities provides other examples. In the case of school deșegregation, the charges are brought against a school system through its Board of Education: It is the system that is defined as deviant and sanctioned. The board members, the superintendent, and the teachers may escape specific definition as deviant. The legal system is geared to defining the organized school system as failing to comply and legal and fiscal sanctions are directed against the organization to coerce compliance. In addition, local organizations such as the NAACP and their national Legal Defense Fund exert pressure to comply.

International conflict situations present numerous examples where one or a number of social systems will define others as deviant and impose sanctions without defining any leaders or members as deviant. To be sure, of course, in some cases both nations and leaders are defined as deviant but there are many cases where they are not. The boycott, the blockade, diplomatic recognition, the loan and other forms of aid are important sanctions for deviance in relations among nations.

I cite these examples solely to call attention to the fact that both within and among social systems, organized units can be defined and sanctioned as deviant without any person who is a member of the organization defined as deviant in the processing of deviance.

If time permitted I would like to say something about how the values, norms, and sanctions of social systems are differentially organized so that organizational deviance is more explicitly dealt with in some social systems than in others. 
It is apparent, for example, that the American social system gives nigh priority to individual rights in the system. Yet we are constantly engaged. in balancing individual against collective interests. In balancing out individual and collective interests, it perhaps becomes more difficult to define and sanction organizational deviance in systems where individual rights occupy the priority they do in our system.

In the American social system, a principal way to sanction organizations is to define the behavior of persons in the organization as deviant, thereby sanctioning the organization by sanctioning its members. Given the importance of leadership in organization, the organization is especially vulnerable to sanctions against its leadership, particularly when those sanctions force a succession in leadership. The decline of the IWW occurred in part because of a coerced succession in leadership.

Yet it would be mistaken to assume that sanctions are not directed against organizations... as. well as individuals. The strike, the sit-in, the boycott; the blockade, the occupation of a territory, the financial subsidy, second and third class mailing privileges, the court order, and police action to coerce compliance are but some of the kinds of sanctions that are generally applied only to organizations when they are deviant. Much neglected in the study of social organization and deviance is the relationship of modes of deviance and the political organization of the society. The literature of deviance has tended to focus either on the deviant in politics, e.g., the authoritarian personality or the "corrupt" boss, or on the "deviant" organization and its role in the political process, e.g., the 
"deviant" movement. . Other matters should be regarded as problematic, however. From the perspective of social organization, the organizational forms and processes and of organized behavior itself in the political process should be regarded as problematic. The organized means such as strategy: and tactics for example may be regarded as deviant in the system. Thus the society defines their "legitimate" use in the political order. All other use in the system will be treated as illegitimate. This is readily apparent if one considers strategies of violence in the political process. The military and the police share a monopoly of its "legitimate" exercise but their exercise must also be "legitimated". The police may exercise force unduly and be faced with charges of "police brutality". Indeed, at the present time it is not the individual officer who is seen as the deviant but the charge is against a police organization and it is"the organization that is to be held accountable.for such failures.

Both means and the ends may be legitimate until they arise in a particular context in the political process, at which point they are defined as illegitimate. 'One may; for example, "legitimately" oppose U. S. foreign"policy and one may legitimately "strike" as a means to negotiable ends.. But an attempt by university professors to stage a walk-out-from classes as a form of protest against U. S. foreign policy in Viet Nam is to open them to charges of deviance within the usually tolerant university community. It is not a legitimate mode of expression in relation to the "ends". A "teach-in" is more likely to be defined as "legitimate". Indeed much of the political dialogue today in the U. S. seems in its organized aspects to raise 
questions about "modes of protest".'in relation to goals. And political organizations or movements themselves may combine in a particular way "deviant". and "highly legitimate forms" making coping with them problematic in the society. Thus McCarthyism and the Minute Men draw upon deviant means in the avowed interest of preservation of the constitutional order. They are thereby less vulnerable to characterizations of deviance.

\section{Conclusion}

We are coming to the end of my remarks. Several things I hope have become apparent in this cursory survey of where the action should be in the study of deviance.

I suggest that we have been preoccupied with defining persons as deviant at the expense of examining organizational deviance. closely related to this is the fact that much of our concern with deviance has focused on violations of the criminal code in western systems, treating deviance under the icivil code as nonproblematic in our theory. We have been preoccupied with suicide and homicide but not with deicide or genocide.. Indeed I am struck by the fact that there is no sociological writing of consequence on genocide. We have been concerned with hidden deviance of individuals and not the visible deviance of organizations.

In brief the general thrust of my remarks has been to suggest that in the study of deviant behavior the action does not lie primarily in motivation to deviant behavior on the one hand nor in cultural and social structure on the other. The action rather is in the.study of social organization--the organizational matrix that encompases the deviant behavior of persons 
and the deviant behavior or organizations. A more general theory can encompass both. Indeed; the theory of organizations is easily adapted to the study of organizational deviance. Perhaps the time has come to remake the scene as well as make it. The action lies not only in a return to actors but to their organization. 


\section{Footnotes}

*Presidential Address, Twenty-Eighth Annual. Meeting of. The Ohio Valley Sociological Society, Dayton, Ohio, April 29 , 1966.

1. Robert K. Merton, "Social Structure and Anomie", American Sociological Review, 3 (1938) 672-682, p. 672.

2. Ibid., p. 672 .

3. Albert K. Cohen, "The Sociology of the Deviant Act: Anomie Theory and Beyond", The American Sociological Review, 30 (February, 1965) 5-14; Erving Goffman, Asylums, Garden City: Anchor Books, Doubleday and Co., Inc., i96 1 ; Howard S. Becker, Outsiders: Studies in The Sociology of Deviance, The Free Press of Glencoe, 1963 .

4. Ibid., p. 9, italics mine.

5. Ibid., p. 163 .

6. Ibid., p. 146, italics mine。

7. Robin Williams, American Society, New York: Alfred A. Knopf, revised edition, 1962, p. 379 .

8. Edwin H. Sutherland, "Is "White-Collar Crime" Crime?", American Sociological Review, X (1945) pp. 132-39.

9. Talcott Parsons, The Social System, Glencoe: The Free Press, 1951, p. 297.

10. Neil J. Smelser, Theory of Collective Behavior, New York: The Free Press of Glencoe, 1963, Chapter X.

11. Philip Selznick, The Organizational Weapon, New York: McGraw Hill, 1952, p. 2 . 